\title{
Hype or Reality: Will Enterprise Systems as a Service Become an Organizing Vision for Enterprise Cloud Computing in Denmark?
}

\author{
Per Svejvig ${ }^{1}$, Torben Storgaard ${ }^{2}$, and Charles Møller ${ }^{3}$ \\ ${ }^{1}$ Department of Business Administration, Aarhus University, Denmark \\ psvelasb. dk \\ ${ }^{2}$ HerbertNathan \& Co, Copenhagen, Denmark \\ ts@herbertnathan.com \\ ${ }^{3}$ Center for Industrial Production, Aalborg University \\ Charles@business.aau.dk
}

\begin{abstract}
Cloud computing is at "the peak of inflated expectations" on the Gartner Hype Cycle from 2010. Service models constitute a layer in the cloud computing model and Software as a Service (SaaS) is one of the important service models. Software as a Service provides complete business applications delivered over the web and more specific when delivering enterprise systems (ES) applications such as ERP, CRM and others we can further categorize the model as an Enterprise Systems as a Service (ESaaS) model. However it is said that ESaaS is one of the last frontier for cloud computing due to security risk, downtime and other factors. The hype about cloud computing and ESaaS made us speculate about our local context, Denmark, what are the current situation and how might ESaaS develop. We are asking the question: Will ESaaS become an organizing vision in Denmark? We used empirical data from a database with more than 1150 Danish organizations using ES, informal contacts to vendors etc. The result of our study is very surprising as none of the organizations in the database apply ESaaS although recent information from vendors indicates more than 50 ESaaS implementations in Denmark. We discuss the distance between the community discourse and current status of real ESaaS implementations.
\end{abstract}

Keywords: Cloud computing, software as a service (SaaS), enterprise systems, organizing vision, institutional theory.

\section{$1 \quad$ Introduction}

Cloud computing is on everybody's lips today and is promoted as a silver bullet for solving several of the past problems with IT by offering pay per use, rapid elasticity, on demand self-service, simple scalable services and (perhaps) multi-tenancy [1]. Cloud computing is furthermore marketed as a cost saving strategy appealing well to the post financial crisis situation for many organizations with cloud's "Opex over Capex story and ability to buy small and, if it works, to go big" [2]. Cloud computing has even been named by Gartner " as the number one priority for CIOs in 2011" [3].

(C) IFIP International Federation for Information Processing 2013 
Gartner position in addition cloud computing at the "peak of inflated expectations" at the Gartner Hype Cycle predicting 2 to 5 years to mainstream adoption [4].

Service models constitute a layer in the cloud computing model and Software as a Service (SaaS) is one of the important types of service models. Software as a Service provides complete business applications delivered over the web and more specific when delivering enterprise systems (ES) applications such as ERP, CRM and others we can further categorize the model as an Enterprise Systems as a Service (ESaaS) model. In this paper we use ESaaS interchangeable with SaaS but also as a more specific concept. As cloud computing is still an evolving paradigm, its definitions, use cases, underlying technologies, issues, risks, and benefits can be refined [5].

Software as a Service (SaaS) embraces cloud applications for social networks, office suites, CRM, video processing etc. One example is Salesforce.com, a business productivity application (CRM), which relies completely on the SaaS model [6] consisting of Sales Cloud, Service Cloud and Chatter Collaboration Cloud [7] residing on "[Salesforce.com] servers, allowing customers to customize and access applications on demand" [6].

However enterprise wide system applications and especially ERP has been considered the last frontier for SaaS where companies has put forward the following reasons preventing them from considering ESaaS (prioritized sequence): (1) ERP is too basic and strategic to running our business, (2) security concerns, (3) ability to control own upgrade process, (4) downtime risk, (5) greater on-premise functionality, (6) require heavy customizations, and finally (7) already invested in IT resources and don't want to reduce staff [8]. A very recent example shows the potential problem with cloud and ESaaS where Amazon had an outage of their cloud services lasting for several days and affecting a large number of customers [9].

Despite these resisting factors there seems to be a big jump in ESaaS interest with $39 \%$ of respondents willing to consider ESaaS according to Aberdeen's 2010 ERP survey, which is a $61 \%$ increase in willingness from their 2009 to 2010 survey [10], this a furthermore supported by a very recent report from Panorama Consulting Group [11] stating the adoption rate of ESaaS to be $17 \%$.

The adoption pattern of ESaaS varies in at least two dimensions company size and application category. Small companies are more likely to adopt SaaS followed by mid-size organizations [8], which might be explained by large companies having a more complex and comprehensive information infrastructure [as defined in 12] compared to small and mid-size companies. CRM applications are more frequent than ERP application [8] where a possible explanation can be the perception of ERP as too basic and strategic to run the business in a ESaaS model.

Most recently, the Walldorf German based ERP vendor SAP have launched an on demand ERP (SaaS) solution: SAP Business By Design that can be seen as prototype ESaaS model[13]. SAP Business By Design is a fully integrated on-demand Enterprise Resource Planning (ERP) and business management software solution for small and medium sized enterprises (SME). It is a complete Software as a Service (SaaS) offering for 10-25 users available on most major markets. However, the real cases are actually hard to locate. 
The previous trends, numbers [e.g. 11] and the statements from Gartner are referring to the global landscape for cloud computing and ESaaS operating at this rather abstract global level. This made us speculate about our local context, Denmark, what is the current situation and how might ESaaS develop specifically in our landscape this framed our research question: Will Enterprise Systems as a Service become an organizing vision in Denmark?

\section{Enterprise Systems as a Service - Global and Local Context}

Cloud computing appears to have emerged very recently as a subject of substantial industrial and academic interest, though its meaning, scope and fit with respect to other paradigms is hotly debated. For some researchers, Clouds are a natural evolution towards full commercialization of Grid systems, while for others they may be dismissed as a mere rebranding of the existing pay-per-use or pay-as-you-go technologies [14].

Cloud computing is a very broad concept and an umbrella term for refined on demand services delivered by the cloud [6]. The multiplicity in understanding of the term is probably fostered by the "beyond amazing hype level" [1] underlining the peak in Gartner's Hype Cycle [4]. Many stakeholders (vendors, analysts etc.) jump on the bandwagon inflating the term and "if everything is a cloud, then it gets very hard to see anything" [1], so we need to be very explicit about using the term. We follow the US National Institute of Standards and Technology (NIST) definition [5]:

Cloud computing is a model for enabling convenient, on-demand network access to a shared pool of configurable computing resources (e.g., networks, servers, storage, applications, and services) that can be rapidly provisioned and released with minimal management effort or service provider interaction.

This cloud model promotes availability and is composed of five essential characteristics, three service models, and four deployment models as illustrated in figure 1 below [15].

The notion of the "cloud" as a technical concept is used as a metaphor for the internet and was in the past used to represent the telephone network as an abstraction of the underlying infrastructure [16]. There are different deployment models for cloud computing such as private clouds operated solely for an organization, community clouds shared by several organizations, public clouds and hybrid clouds as a composition of two or more clouds (private, community or public) [17]. The term virtual private clouds have also entered the scene analogous to VPN. There is a controversy about whether private clouds (virtual or not virtual) really is cloud computing [1].

Cloud computing can be divided into three layers namely [6]: (1) Infrastructure as a Service (IaaS), (2) Platform as a Service (PaaS) and (3) Software as a Service (SaaS). The focus in this paper is on the enterprise systems as a service (ESaaS) where "SaaS is simply software that is delivered from a server in a remote location to your desktop, and is used online" [18]. ESaaS usage is expected to expand in 2011 [19]. 
The air is also charged with cloud computing and SaaS in Denmark. Many of the issues discussed in this paper apply to the local Danish context, but there are also additional points to mention. First, Denmark has a lot of small and medium sized organizations (SME's) which are expected to be more willing to adapt ESaaS [8].

Second, the Local Government Denmark (LGDK) (an interest group and member authority of Danish municipalities) tried to implement a driving license booking system based on Microsoft's Azure PaaS, but ran into technical and juridical problems. The technical problems were related to the payment module, logon and data extract from the cloud based solution [20]. The legal issue was more serious as LGDK (and the municipalities) was accused by the Danish Data Protection Agency to break the act on processing of personal data, especially about location of data [21]. LGDK decided to withdraw the cloud solution and replaced it with an on premise solution with the comments "cloud computing is definitely more difficult, and harder, than what is mentioned in the booklets" [20].

Finally, the CIO from "The LEGO Group", a well-known Danish global enterprise within toy manufacturing, stated in news media that "cloud is mostly hot air". Cloud can only deliver a small fraction of the services that LEGO need and cannot replace their "customized SAP, Microsoft, Oracle and ATG [e-commerce] platforms with end to end business process support". LEGO are using cloud to specific point solutions such as "spam and virus filtering", "credit card clearing" and load-testing of applications but "[t]o put our enterprise-platform on the public cloud is Utopia" [22].

This section has described the global and local context for ESaaS and both contexts will probably influence Danish organizations and their willingness to adopt these solutions. In the next section we will look into a theoretical framing of the cloud computing impact on the enterprise systems in Denmark.

\section{IS Innovations as Organizing Visions}

An Organizing Vision (OV) can be considered a collective, cognitive view of how new technologies enables success in information systems innovation. This model is used to analyze ESaaS in Denmark.

Swanson and Ramiller (1997) takes institutional theory into IS research and propose the concept of organizing vision in IS innovation, which they define as "a focal community idea for the application of information technology in organizations" [23]. Earlier research has argued that early adoption of a technological innovation is based on rational choice while later adoption is institutionalized. However Swanson and Ramiller suggest that institutional processes are engaged from the beginning. Interorganizational communities create and employ organizing visions of IS innovations. Examples are CASE tools, e-commerce, client server [24] and Application Service Providers (ASP) [25] and comparable to management fads like BPR, TQM and quality circles $[25,26]$. The organizing vision is important for early and later adoption and diffusion. The vision supports interpretation (to make sense of the innovation), legitimation (to establish the underlying rationale) and mobilization (to activate, motivate and structure the material realization of innovation) $[23,25]$. 
The OV model presents different institutional forces such as community discourse, community structure and commerce and business problematic, which are used in the analysis of ESaaS in Denmark.

\section{$4 \quad$ Research Methodology}

The research process started early 2011 where we applied different data collection methods: (1) Queries into HNCO database with ERP, CRM systems, (2) Informal dialogue with ES vendors, and finally (3) Literature search of cloud computing and SaaS (research and practitioner oriented). The second author is employed at a Herbert Nathan \& Co (HNCO), a Danish management consulting company within area of ERP, they maintains a database of top 1000 companies in Denmark and their usage of enterprise systems. However we did not find any customers in the database using ESaaS, which were surprising. We repeated our study in spring 2012 and surprisingly got the same result as one year ago. ES as a Service is apparently not used by Top 1000 companies in Denmark. However informal talk with vendors indicates that there might be about 50 references in Denmark, but we have only been able to confirm a small number of these claimed references.

\section{$5 \quad$ Analysis}

The table below shows the analysis concerning ESaaS as an organizing vision (adapted from Figure 3):

Table 1. Analysis of ESaaS as an organizing vision

\begin{tabular}{l}
\hline $\begin{array}{l}\text { Institutional } \\
\text { forces }\end{array}$ \\
\hline
\end{tabular}

Community discourse
Cloud computing has been named by The global discourse are part of the Gartner "as the number one priority local Danish discourse, but local stofor CIOs in 2011" [3] ries does also shape the local context

Gartner position cloud computing at Denmark has a lot of small and methe "peak of inflated expectations" at dium sized organizations (SME's) the Gartner Hype Cycle predicting 2 which are expected to be more willing to 5 years to mainstream adoption [4] to adapt ESaaS [8]. That might fertilAberdeen survey and Panorama Con- ize the ground for faster adoption of sulting Group report shows a big jump ESaaS in interest in ESaaS / SaaS [10, 11]

Amazon had an outage of their cloud services lasting for several days and affecting a large number of customers [9]. This case received very much press coverage and it would be natural to expect it to have a negative impact on the perception of cloud computing
The Local Government Denmark (LGDK) tried to implement a driving license booking system based on Microsoft's Azure PaaS, but ran into technical and juridical problems [20]. The CIO from "The LEGO Group" stated in news media that "cloud is mostly hot air". Cloud can only deliv- 


\begin{tabular}{lll}
\hline $\begin{array}{l}\text { Institutional } \\
\text { forces }\end{array}$ & Global Context & Local Context \\
\hline & & er a small fraction of the services that \\
LEGO need [22]
\end{tabular}

Table 1 above shows the conditions for ESaaS to become an organizing vision although it would be too early to claim it is an organizing vision especially because the link to practice appears to be uncertain. Our knowledge about the 50 implementations in Denmark is very limited and we do not know the status of the implementations (pilots, just started, normal operation, abandoned etc.).

\subsection{Discussions}

First of all the research indicate that the organizing vision of ESaaS in Denmark is perhaps on a too preliminary stage to make sense. The evidence are scarce or inaccessible which indicate that the idea is either not existing or at an immature state. Given the vast amount of interest, we assume that the concept is either immature or that the ideas will emerge under a different heading that we have not been able to identify.

In any cases we can use the idea of the organizing vision as a normative model for the evolution of the cloud computing concept in an enterprise systems context. This is comparable to Gartner's hype cycle: After the initial peak of inflated expectations we will gradually move into the slope of enlightenment. The organizing vision could be a normative model for making sense of the developments. But only future research will tell. 
As a final comment to the organizing vision of ESaaS the following quote from Larry Ellison, the CEO of Oracle from September 2008 sum up the experiences:

The interesting thing about cloud computing is that we've redefined cloud computing to include everything that we already do. I can't think of anything that isn't cloud computing with all of these announcements. The computer industry is the only industry that is more fashion-driven than women's fashion. Maybe I'm an idiot, but I have no idea what anyone is talking about. What is it? It's complete gibberish. It's insane. When is this idiocy going to stop?

\section{Conclusion}

This paper has sought to further our understanding of cloud computing, SaaS and with special focus on ESaaS. We described the global and local context for cloud computing and ESaaS / SaaS. We furthermore presented institutional theory extended by the work of Swanson and Ramiller about their concept of organizing visions. We asked the question: Will ESaaS become an organizing vision in Denmark. The paper can give some initial and indicative answers to the question that the community discourse support ESaaS as an organizing vision but the current status of real ESaaS implementations is uncertain.

The paper has only been able to scratch the surface and to give some initial thoughts about ESaaS in the local context. However the paper sets the stage for a longerterm research challenges about ESaaS. First, an obvious extension of this paper is to study the Danish market in much more detail by interviewing the actors in the community structure especially ESaaS customers. Second, comparative studies between countries would also be interesting, does such an organizing vision as ESaaS diffuse similarly or differently and what shapes the diffusion and adoption. Finally, the theoretical framework by Swanson and Ramiller are appealing to study the adoption and diffusion of technology possible extended by this paper's approach with the global and local context.

\section{References}

1. Wohl, A.: Cloud Computing. In: Simon, P. (ed.) The Next Wave Technologies - Opportunities in Chaos, pp. 59-78. John Wiley \& Sons, Hoboken (2010)

2. Schultz, B.: Enterprise Cloud Services: the agenda. CIO Magazine (2011), http: / /www.cio.com/article/print/ 662607 (cited March 14, 2011)

3. Golden, B., Cloud CIO: 5 Key Pieces of Rollout Advice. CIO Magazine (2011), http://www.cio.com/article/print/679070 (cited April 11, 2011)

4. Fenn, J.: Hype Cycle for Emerging Technologies, Gartner, p. 10 (2010)

5. Mell, P., Grance, T.: The NIST Definition of Cloud Computing (2009), http://www.nist.gov/itl/cloud/upload/cloud-def-v15.pdf (cited April 25, 2011) 
6. Voorsluys, W., Broberg, J., Buyya, R.: Introduction to Cloud Computing. In: Buyya, R., Broberg, J., Goscinski, A.M. (eds.) Cloud Computing Principles and Paradigms, pp. 3-42. Wiley, New Jersey (2011)

7. Salesforce.com. The leader in customer relationship management (CRM) \& cloud computing (2011), http: / / www . sales force. com (cited April 22, 2011)

8. Aberdeen Group, SaaS ERP: Trends and Observations, A. Group (ed.) (2009)

9. Thibodeau, P.: Amazon Outage Sparks Frustration, Doubts About Cloud. CIO Magazine (2011), http: / /www. cio.com/article/print/ 680329 (cited March 14, 2011)

10. Subramanian, K.: Big Jump in SaaS ERP Interest (2010), http: / / www.cloudave.com/8058/big-jump-in-saas-erp-interest / (cited March 13, 2011)

11. Panorama Consulting Group, 2011 ERP Report, Panorama Consulting Group (2011)

12. Hanseth, O., Lyytinen, K.: Design theory for dynamic complexity in information infrastructures: the case of building internet. Journal of Information Technology 25(1), 1-19 (2010)

13. SAP. SAP Business ByDesign (2012), http: / / www . sap. com/solutions / technology/cloud/business-bydesign/highlights/index. epx (cited April 28, 2011)

14. Antonopoulos, N., Gillam, L.: Cloud Computing: Principles, Systems and Applications. Springer-Verlag London Limited (2010)

15. Williams, M.I.: A quick start guide to cloud computing: moving your business into the cloud. Kogan Page Limited (2010)

16. Baan, J.: Business Operations Improvement, The New Paradigm in Enterprise IT. Cordys Holding B.V. (2010)

17. Beck, K., et al.: Agile Software Development Manifesto (2001), http: / / agilemanifesto.org/ (cited July 1, 2009)

18. Wohl, A.: Software as a Service (SaaS). In: Simon, P. (ed.) The Next Wave Technologies Opportunities in Chaos, pp. 97-113. John Wiley \& Sons, Hoboken (2010)

19. O'Neill, S.: Cloud Computing in 2011: 3 Trends Changing Business Adoption. CIO Magazine (2011), http://www.cio.com/article/print/663316 (cited March 14, 2011)

20. Elkær, M.: Derfor gik kommunernes cloud-forsøg i vasken. In: Computerworld (2011)

21. Elkær, M.: Datatilsynet farer i flæsket på KL over cloud-flop. In: Computerworld (2011)

22. Nielsen, J.: LEGO: Skyen er mest varm luft. In: Comon (2011)

23. Swanson, E.B., Ramiller, N.C.: The Organizing Vision in Information Systems Innovation. Organization Science 8(5), 458-474 (1997)

24. Ramiller, N.C., Swanson, E.B.: Organizing Visions for Information Technology and the Information Systems Executive Response. Journal of Management Information Systems 20(1), 13-50 (2003)

25. Currie, W.L.: The organizing vision of application service provision: a process-oriented analysis. Information and Organization 14(4), 237-267 (2004)

26. Abrahamson, E., Fairchild, G.: Management Fashion: Lifecycles, Triggers, and Collective Learning Processes. Administrative Science Quarterly 44(4), 708-740 (1999) 